\title{
Assisting families at Risk of Poverty in the Context of Social Services
}

\section{J. Tuma (Jiri Tuma)1,2, Z. Ondrusova (Zlatica Ondrusova)1}

${ }^{1}$ St. Elisabeth University of Health and Social Sciences, Bratislava, SK

Original Article

${ }^{2}$ College of Physical Education and Sport PALESTRA, Prague, Department of Pedagogy and Psychology, CZ

\section{E-mail address:}

jirkatuma@centrum.cz

\section{Reprint address:}

Jiri Tuma

College of Physical Education and Sport PALESTRA, Prague

Department of Pedagogy and Psychology

Slovacikova 400/1

19700 Prague 19-Kbely

CZ

Source: Clinical Social Work and Health Intervention

Volume: 9

Issue: 2

Pages: $101-105$

Cited references: 10

\section{Reviewers:}

Vlastimil Kozon

Allgemeines Krankenhaus - Medizinischer Universitätscampus, Vienna, AT

Daniel J. West, Jr.

University of Scranton, Department of Health Administration and Human Resources, USA

\section{Key words:}

Social services. Poverty. Assisting families. Risk of poverty.

\section{Publisher:}

International Society of Applied Preventive Medicine i-gap

CSWHI 2018; 9(2): 101 - 105; DOI 10.22359/cswhi_9_2_15 @ 2018 Clinical Social Work and Health Intervention

\section{Abstract:}

Objective: The aim of the research was to identify forms of assistance and use of Social Services by people from families at risk of poverty.

Design: Quantitative Research.

Participants: The characteristic sample group was a target group of adults (18 years and over) in the Czech Republic in the capital city of 
Prague. Research centers have been deliberately chosen for the Social Services Centers: the Salvation Army Day Center in Tusar Street; the Day Center of the Archdiocesan Charity in Prague 8 Pernerova Street; the Non-Profit Organization of Hope in Prague 2 U Bulhara Street. Altogether, 300 questionnaires were distributed to respondents, of which 253 questionnaires were correctly filled. The sample comprised 253 respondents (51 women and 202 men).

Methods: The research was conducted in the winter months 2016-2017 through a questionnaire survey. The results were evaluated by statistical evaluation of the chi-quadrate of the test with $95 \%$ confidence and dependence was verified by the Pearson Contingency Coefficient.

Results: The tables show that the availability of assistance to families at risk of poverty in Social Services is sufficient within 60 years. It can be said that the ignorance of young families at risk of poverty which do not know of the available Social Services, plays an important role.

Conclusion: Research shows that mutual assistance and cooperation between Social Services and the availability of information, programs on existing services for families at risk of poverty are very important in this area.

\section{Introduction}

The issue of families at risk of poverty is the result of many influences and areas and it is a complicated, internally differentiated social, political, economic, health, legal and security issue (Arndt, Tarp, 2017). It turns out that the complex work with families at risk of poverty requires the simultaneous use of a number of other services and work areas that are not mentioned in the Social Services Act but are necessary to work with these families. The aim is to identify the forms of assistance and the use of Social Services by persons from families at risk of poverty, with their help, offer a possible supplement or extension of these services (Matousek, Kolackova, Kodymova, 2010). It is also necessary to describe the most common causes of the family at risk of poverty and prevention, which is not yet a strategy for us. However, poverty prevention is more effective and financially less demanding than family consequences. Social Services represent a clear and legal offer to address the social exclusion of families at risk of poverty (Mares, 1999). Social Service providers must offer their services primarily in the context of current social policy. Loss from family breakdown, loss of employment or housing is often the culmination of the complex life situation of a person and a direct reaction to the fact that this situation or a certain phase of life has not been dealt with. The theme is the challenge and the moral duty of society to seek answers to the theoretical and practical questions to help threatened families (Matousek et al., 2011).

\section{Methods}

The research was conducted from December 2016 to February 2017 through a questionnaire survey. The basic set was made up of adults - individuals from families at risk of poverty (18 years or more) in the capital city of Prague by means of deliberate choice (Fejtkova, 2017). The following centers of Social Services in Prague were used for research: the Salvation Army Day Center 
in Tusar Street; the Day Center of the Archdiocesan Charity in Prague 8 in Pernerova Street; the Non-Profit Organization of Hope in Prague 2 U Bulhara Street. Altogether 300 questionnaires were distributed, of which 253 were filled in correctly $(84.3 \%)$. The questionnaire contained a total of 30 questions to identify goals, research questions and hypotheses. The quantitative research used, helped to obtain data that meets the criteria of validity and reliability. Results were

\section{Results}

From Pivotable 1 it is clear that the length of stay of families at risk of poverty in Social Services is not influenced by the education of the respondent. Statistical test value $=31.4$ with 20 degrees of freedom. The value of the Pearson Contingency Coefficient is 0.2198 . Dependence is considered to be stronger when the coefficient value is closer to one. It can therefore be said that this is a weak association.

Pivotable 1: Calculation of the hypothetical relative frequency of length of the vulnerable person by poverty.

\begin{tabular}{|l|r|r|r|r|r|r|r|}
\hline \multirow{2}{*}{ Education } & \multicolumn{6}{|c|}{ How long have you been a person at risk of poverty? } \\
\cline { 2 - 8 } & $0-1$ & $2-5$ & $6-10$ & $11-15$ & $16-20$ & $\begin{array}{l}\text { More than } \\
\text { 20 years }\end{array}$ & Total \\
\hline Elementary School & 18.4 & 45,2 & 41,0 & 21,0 & 3,2 & 4,2 & 133 \\
\hline $\begin{array}{l}\text { Taught without leaving } \\
\text { examination }\end{array}$ & 10.4 & 25,5 & 23,1 & 11,9 & 1,8 & 2,4 & 75 \\
\hline Secondary school with GCSE & 5,7 & 13,9 & 12,6 & 6,5 & 1,0 & 1,3 & 41 \\
\hline Higher vocational school & 0,1 & 1,0 & 0,9 & 0,5 & 0,1 & 0,1 & 3 \\
\hline College & 0,1 & 0,3 & 0,3 & 0,2 & 0,0 & 0,0 & 1 \\
\hline Total & 35 & 86 & 78 & 40 & 6 & 8 & 253 \\
\hline
\end{tabular}

processed using pivot tables and chi-square of the independence test ( $\alpha=0.95$ ) with 95\% confidence. Dependence was verified using the Pearson Contingency Coefficient. The results of the work were compared with related research in the Czech Republic and abroad.
From Pivotable 2, it is clear that under the age of 60 there is sufficient availability of assistance and social care for people at risk of poverty. It can be said that the ignorance of young families who do not know about

Pivotable 2: Calculation of the hypothetical relative frequency of availability of social care provision.

\begin{tabular}{|c|c|c|c|c|}
\hline \multirow{2}{*}{ Age } & \multicolumn{2}{|c|}{ What is the availability of social care provision? } & \multirow{2}{*}{ Total } \\
\cline { 2 - 5 } & Sufficient & Inadequate & I do not know & \\
\hline Up to 20 years including & 20,3 & 6.3 & 3,4 & 30 \\
\hline $21-30$ & 31,8 & 9.8 & 5,4 & 47 \\
\hline $31-40$ & 39,9 & 12,4 & 6,8 & 59 \\
\hline $41-60$ & 71,0 & 22,0 & 12,0 & 105 \\
\hline $61 \&$ over & 8,1 & 2,5 & 1,4 & 12 \\
\hline Total & 171 & 53 & 29 & 253 \\
\hline
\end{tabular}


the available Social Services plays an important role. The value of the Pearson Contingency Coefficient is 0.2786 . Dependence is considered to be stronger when the coefficient value is closer to one. It can therefore be said that this is a weak association.

\section{Discussion}

According to the survey, $78.7 \%$ of respondents are provided with adequate Social Services; $23 \%$ of respondents do not have a Social Service offer and $12.3 \%$ of respondents have no opinion on the question (Dovidio et al., 2006). In the case of proposals for improvement of provided Social Services, less than $20 \%$ of housing assistance in the case of families at risk of poverty, which needed Social Services with respect to their age and health, expressed $15.4 \%$ better access; $14,6 \%$ of the interviewed respondents would welcome the therapeutic services; less than $14 \%$ of respondents reported $12.3 \%$ improvement in Health Care and 9.9\% legal counseling (Matousek et al., 2017). As shown by the research, the capacity of Social Services is sufficient for $64 \%$ of respondents, insufficient for $25.3 \%$ and less than $11 \%$ of respondents did not have their own opinion on the question. From the results of these frequencies, it is clear that in almost $40 \%$ of respondents divorce was the cause of poverty, $26.1 \%$ of respondents declared a job loss; $12.6 \%$ came to this situation by mistake (gambling, alcohol, drugs); $9 \%$ for reasons of health; $4.7 \%$ reported the cause of release from prison; 9 respondents $(3.6 \%)$ were the cause of the loss of housing (Kaduschin, Harkness, 2002). Other reasons were reported by $5.1 \%$ of respondents, i.e. debt, widowhood, violence and abuse in relation to their partnership or their own decision. From the above results, it can be stated that loss of employment is the second most serious cause. As can be seen, most respondents had basic education, which was
$52.6 \%$ of the total number of respondents. The second most frequent group was the unemployed, who accounted for $29.6 \%$ of the total number of respondents. Secondary school with graduation was $16.2 \%$, and the higher vocational school with the highest education was the smallest group (1.6\%). It is given that people with lower education are more likely to be more vulnerable than those with higher education (Rist et al., 2017). The response of respondents to the question of what is important in their lives is that $37.2 \%$ indicate the importance of the family; $20.6 \%$ of respondents said that alcohol and drugs are important for them; 11.9\% housing; $11.5 \%$ of employment (Koukolik, Drtilova, 2001). Other causes were 4.7\% money; leisure time; gambling. It is clear from the results that $69.9 \%$ of the total number of respondents expressed a positive opinion on the reintegration of vulnerable families through Social Services into society. $47 \%$ of respondents expressed a very positive opinion; $12.6 \%$ expressed a negative opinion; $17.4 \%$ did not have a clear opinion on the issue.

\section{Conclusion}

Poverty is often the result of a person's difficult life situation and a direct response to inability to handle this situation. As a result of research, one of the main reasons is family breakdown and another factor is the loss of employment. People suffer greatly from psychological and somatic diseases, and many people have health complications and should therefore work to restore social skills. Social Services, Social Counseling and Therapy are important for families at risk of poverty and in an unfavorable social situation, but interpersonal relationships have irreplaceable living values. Addressing this problem is important for interconnection and cooperation between services 
at all levels, as the issue of helping families at risk of poverty is interdisciplinary and requires the involvement of multiple areas and a functional social policy.

\section{References}

1. ARNDT CH, TARP F (2017) Measuring poverty and wellbeing in developing countries. New York: Oxford University, 347 p. ISBN 978-0-19-874480-1.

2. DOVIDIO JF et al. (2006) The social psychology of prosocial behavior. New Jersey: Lawrence Erlbaum Associates, 2006, 408 p. ISBN 0-8058-4935-1.

3. FEJTKOVA O et al. (2017) Poverty, charity and social welfare in Central Europe in the 19th and 20th centuries. Newcastle upon Tyne: Cambridge Scholars, 449 p. ISBN 978-1-4438-4497-0.

4. KADUSHIN A, HARKNESS D. (2002) Supervision in social work. New York:
Columbia University Press 576 p. ISBN 0-231-12094-X.

5. KOUKOLIK F, DRTILOVA J (2001). Life with deprivation. Evil for every day. Prague: Galen, 390 p. ISBN 80-7262-088-6.

6. MARES P (1999) Sociology of inequality and poverty. Prague: Sociological publishing, 248 p. ISBN 80-85850-61-3.

7. MATOUSEK O et al. (2011). Social Services. Prague: Portal, 200 p. ISBN 978-80262-0041-3.

8. MATOUSEK O, KOLACKOVA J, KODYMOVA P (2010) Social work in practice. Prague: Portal, 352 p. ISBN 978-80-7367818-0.

9. MATOUSEK O et al. (2017) Child traumatized in close relationships. Prague: Portal, 208 p. ISBN 978-80-262-1242-3.

10. RIST RC et al. (2016) Poverty, inequality and evaluation. Washington: World Bank Group, 313 p. ISBN 978-1-4648-0703-9. 